\title{
APLIKASI PENENTUAN KELAYAKAN PENERIMA KREDIT PADA KOPDIT SWASTI SARI MENGGUNAKAN METODE PROFILE MATCHING
}

\author{
Maximilianus Benge ${ }^{1}$, Frengky Tedy ${ }^{2}$, Yovinia C. Hoar Siki ${ }^{3}$ \\ ${ }^{123}$ Universitas Katolik Widya Mandira Kupang \\ Jalan Jend. Achmad Yani No.50-52, Kota Kupang \\ ${ }^{1}$ amosbenge01@gmail.com, ${ }^{2}$ fredyondang@gmail.com, ${ }^{3}$ yoviniacarmeneja@ gmail.com
}

Abstrak - KSP Kopdit Swasti Sari adalah salah satu koperasi kredit yang ada di Nusa Tenggara Timur. Salah satu kegiatan yang dilakukan oleh KSP Kopdit Swasti Sari untuk meningkatkan kesejahteraan anggotanya adalah memberikan kredit kepada anggotanya. Tapi prosedur pelayanan kredit di KSP Kopdit Swasti Sari masih belum efektif dan efisien. Oleh karena itu KSP Kopdit Swasti Sari membutuhkan suatu metode yang terkomputerisasi guna mengefisiensi kinerjanya. Metode Profile Matching dalam sistem pendukung keputusan adalah salah satu metode yang dapat diterapkan guna memberikan solusi terhadap masalah yang ada. Sistem ini mempu menentukan anggota yang layak menerima kredit selain itu juga memudahkan anggota dalam proses administrasi seperti pendaftaran dan transaksi.

Kata Kunci- Kredit, sistem pendukung keputusan, profile matching

Abstract-KSP Kopdit Swasti Sari is one of the credit cooperatives in East Nusa Tenggara. One of the activities carried out by the KSP Kopdit Swasti Sari to improve the welfare of its members is to provide credit to provide credit to its members. However, the credit service procedure at the KSP Kopdit Swasti Sari is still not effective and efficient. Therefore, the KSP Kopdit Swasti Sari requires a computerized method in order to streamline its performance. The profile matching method in a decision support system is one method that can be applied to provide solutions to existing problems. This system is able to determine which members are eligible for credit. Besides, it also makes it easier for members in administrative processes such as registration and transactions.

Keywords - Credits, decision support system, profile matching

\section{PENDAHULUAN}

Salah satu koperasi kredit yang ada di Nusa Tenggara Timur ialah KSP Koperasi Kredit (Kopdit) Swasti Sari yang didirikan pada tanggal 10 Februari 1988. KSP Kopdit Swasti Sari memiliki cabang yang berlokasi di Jl. Sumba No.3 C Kel. Fatubesi Kec. Kota Lama, Kota Kupang. Salah satu kegiatan yang dilakukan oleh KSP Kopdit Swasti Sari untuk menyejahterakan anggotanya adalah memberikan kredit kepada anggotanya.

Pemberian kredit adalah hal yang penting sehingga membutuhkan pelayanan yang efektif dan efisien. Namun, prosedur pelayanan administrasi kredit di KSP Kopdit Swasti Sari masih belum efektif dan efisien. Seringkali, pemberian kredit tidak tepat sasaran kepada anggotanya oleh karena belum menerapkan sebuah metode matematis dalam menentukan anggota yang layak menerima kredit. Metode matematis yang diterapkan juga bertujuan untuk mencegah terjadinya kelalaian pinjaman.

Berikut adalah data statistik jumlah anggota, peminjam dan kelalaian pinjaman kredit dalam empat tahun terakhir:
TABEL 1

JUMLAH PEMINJAM DAN KELALAIAN PINJAMAN

\begin{tabular}{|l|l|l|l|}
\hline Tahun & Anggota & Peminjam & $\begin{array}{l}\text { Kelalaian } \\
\text { Pinjaman }\end{array}$ \\
\hline 2016 & 25.338 & 3.482 Orang & $\begin{array}{l}\text { Rp. } \\
15.411 .400 .00\end{array}$ \\
& Orang & & $\begin{array}{l}\text { Rp. } \\
19.701 .693 .900\end{array}$ \\
\hline 2017 & 28.598 & 2.352 Orang \\
& Orang & & $\begin{array}{l}\text { Rp. } \\
26.334 .851 .080\end{array}$ \\
\hline 2018 & 33.386 & 3.330 Orang & \\
& Orang & 3.053 Orang & $\begin{array}{l}\text { Rp. } \\
24.520 .858 .050\end{array}$ \\
\hline 2019 & 39.529 & & \\
& Orang & &
\end{tabular}

Berdasarkan data jumlah anggota koperasi, ratarata jumlah anggota yang harus dilayani mencapai ratusan orang per hari. Sedangkan, pegawai yang bertugas melayani kredit hanya berjumlah lima orang dengan rincian tugas: dua petugas pada bagian administrasi, satu pegawai pada bagian analis kredit, dan dua petugas sebagai penerima barang jaminan. Hal ini menimbulkan antrian pelayanan yang panjang karena adanya ketidakseimbangan antara jumlah petugas dengan jumlah anggota yang dilayani per harinya. Oleh karena itu, KSP Kopdit Swasti Sari membutuhkan suatu metode yang terkomputerisasi guna mengefisiensi kinerjanya. Metode profile Matching dalam sistem pendukung keputusan adalah 
salah satu metode yang dapat diterapkan guna memberikan solusi terhadap masalah yang ada.

Profile matching adalah metode yang digunakan dalam membantu pengambilan keputusan dimana kompetensi individu harus memenuhi atau mencapai bobot nilai tertentu yang telah ditentukan. Dalam proses tersebut akan dilakukan proses pembanding antara kompetensi individu ke dalam kompetensi standar, dalam hal ini profil anggota yang ideal, sehingga dapat diketahui perbedaan kompetensinya proses ini biasa disebut gap.

Berdasarkan uraian permasalahan yang ada, maka dalam penelitian ini akan di rancang bangun sebuah "Aplikasi Penentuan Kelayakan Penerima Kredit pada KSP Kopdit Swasti Sari Menggunakan Metode Profile Matching". Aplikasi ini berbasis website yang diharapkan dapat memudahkan anggota dalam melakukan pengajuan kredit secara efektif dan efisien, dan juga calon anggota baru dimudahkan dalam melakukan pendaftaran sebab aplikasi tersebut menyediakan form yang berfungsi untuk pendaftaran anggota baru serta informasi-informasi yang berkaitan dengan KSP Kopdit Swasti Sari.

\section{TINJAUAN PUSTAKA}

A. Sistem Pendukung Keputusan (Decission Support System)

Sistem pendukung keputusan merupakan metodologi terkomputerisasi yang dipakai dalam memecahkan berbagai masalah dengan menggunakan data yang ada sebagai tolak ukur pengambilan keputusan.

Adapun pengertian sistem pendukung keputusan menurut para ahli:

- Menurut (Pinem et al., 2017) Sistem pendukung keputusan (Decision Support System) merupakan suatu pendekatan (atau metodologi) untuk mendukung pengambil keputusan.

- Menurut (Rohayani, 2013) suatu sistem interaktif yang mendukung dalam pengambilan keputusan melalui alternatif-alternatif yang diperoleh dari hasil pengolahan data.

\section{B. Metode Profile Matching}

Adapun pengertian metode profile matching menurut para ahli:

- Menurut (Pinem et al., 2017) adalah metode pengambilan keputusan yang dapat diasumsikan bahwa terdapat tingkatan variabel prediktor yang dijadikan acuan untuk dipenuhi.

- Menurut (Tharo \& Utama Siahaan, 2016) metode profile matching adalah sebuah mekanisme pengambilan keputusan dengan mengasumsikan bahwa terdapat tingkat variabel predikator yang ideal yang harus dipenuhi oleh subjek yang teliti.

- Menurut (Syarifudin \& Ananta, 2015) Model Pencocokan Profil (Profile Matching) adalah suatu proses yang sangat penting dalam manajemen SDM dimana terlebih dahulu ditentukan kompetensi (kemampuan) yang dibutuhkan agar diperoleh hasil maksimum dari kriteria.

- Menurut (purwanto, 2017) mekanisme pengambilan keputusan terutama dalam manajemen sumber daya manusia untuk menentukan suatu jabatan dengan kualifikasi yang telah ditetapkan.

\section{Kriteria dan Penilaian Kredit}

Dalam proses penentuan kelayakan kredit dengan menggunakan metode profile matching harus melihat dari kriteria-kriteria yang telah ditentukan sebagai berikut:

TABEL II KRITERIA-KRITERIA

\begin{tabular}{|c|l|l|}
\hline No & Kriteria & Jenis \\
\hline 1 & C1 - Pekerjaan & Core factor \\
\hline 2 & C2 - Penghasilan & Core factor \\
\hline 3 & C3 - Besar pinjaman & Core factor \\
\hline 4 & C4 - Tujuan pinjaman & Secondary factor \\
\hline 5 & C5 - Barang jaminan & Secondary factor \\
\hline 6 & C6 - Simpanan & Core factor \\
\hline
\end{tabular}

\section{Proses Perhitungan Profile Matching}

1. Perhitungan kompetensi GAP

Setelah anggota mengajukan kredit dengan kriteria-kriteria yang telah ditetapkan, selanjutnya akan dilakukan perhitungan pemetaan gap kompetensi dimana yang dimaksud dengan gap disini adalah selisih antara bobot kriteria anggota dan bobot kriteria pencapaian/standar, rumus untuk mencari selisih gap adalah sebagai berikut:

GAP = bobot kriteria anggota - bobot kriteria pencapaian

2. Pembobotan

Setelah selisih nilai GAP didapatkan, selanjutnya setiap kriteria anggota diberi bobot nilai sesuai ketentuan pada tabel bobot nilai GAP. Dibawah ini:

TABEL III BOBOT NILAI GAP

\begin{tabular}{|c|c|c|}
\hline No & Selisih & Bobot \\
\hline 1 & 0 & 5 \\
\hline 2 & 1 & 4.5 \\
\hline 3 & -1 & 4 \\
\hline 4 & -2 & 3.5 \\
\hline 5 & 2 & 3 \\
\hline 6 & 3 & 2.5 \\
\hline 7 & -3 & 2 \\
\hline 8 & 4 & 1.5 \\
\hline 9 & -4 & 1 \\
\hline 10 & 5 & 0.5 \\
\hline 11 & -5 & 0 \\
\hline 12 & 6 & -1 \\
\hline
\end{tabular}


a. Perhitungan core factor dan secondary factor

Setelah menentukan bobot nilai GAP pada kriteria anggota, setiap aspek dikelompokkan menjadi 2 kelompok yaitu core factor dan secondary factor.

1) Perhitungan core factor

Page | 124

keterangan:

NCT = nilai rata-rata Core Factor

$\sum N C=$ jumlah total nilai Core Factor

$\sum I C=$ jumlah item Core Factor

2) Perhitungan secondary factor

$N S T=\frac{\Sigma \mathrm{NS}}{\Sigma I S}$

keterangan:

$N S T=$ nilai rata-rata Secondary Factor

Factor

$\sum N S \quad=$ jumlah total nilai Secondary

$\sum I S=$ jumlah item Secondary Factor

\section{b. Perhitungan nilai total}

Dari hasil pencarian nilai rata-rata dari Core Factor dan Secondary Factor, berikutnya dihitung nilai total dilihat dari rata-rata nilai Core Factor dan Secondary Factor seperti dibawah ini:

Rumus: $(x) \% N C F+(y) \% N S F=N$

Keterangan:

$N=$ hasil penilaian

$N C F=$ nilai rata-rata Core Factor

$N S F=$ nilai rata-rata Secondary Factor

$x=$ nilai $\%$ yang diinputkan untuk Core factor yaitu $60 \%$

$y=$ nilai $\%$ yang diinputkan untuk Secondary factor yaitu $40 \%$

\section{c. Penentuan kelayakan kredit}

Hasil akhir dari proses profile matching adalah penentuan kelayakan apakah kredit yang diajukan diterima atau ditolak. Setelah setiap kredit anggota mendapat hasil akhir maka dapat ditentukan nilai ratarata yang harus dicapai agar kredit tersebut diterima, berdasarkan hasil keputusan oleh pihak kopdit swasti sari ditetapkan nilai rata-rata yang harus dicapai ialah 2.5

\section{HASIL DAN PEMBAHASAN}

\section{A. Halaman Antar Muka}

Antar muka atau interface yang digunakan dalam sistem pendukung keputusan kelayakan kredit ini terdiri dari berbagai halaman diantaranya:
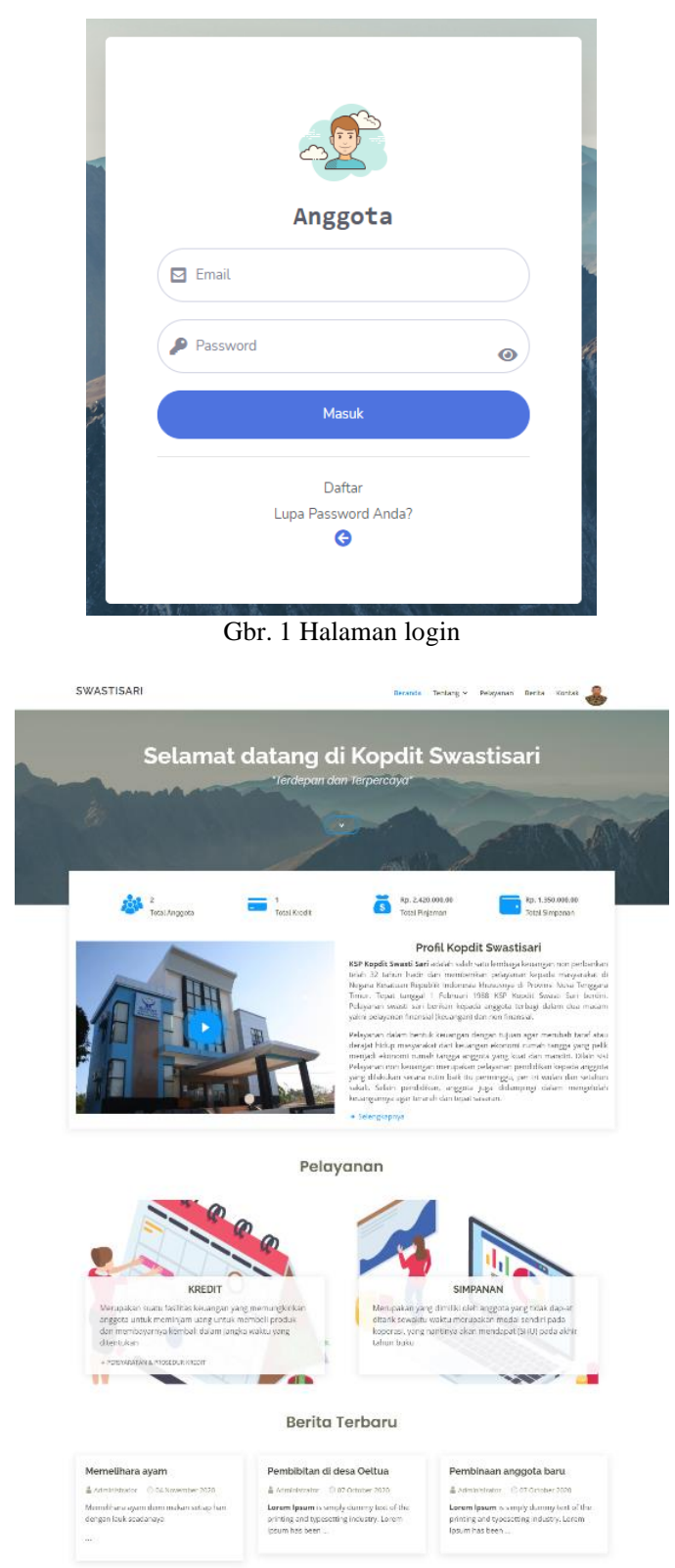

Gbr. 2 Halaman beranda

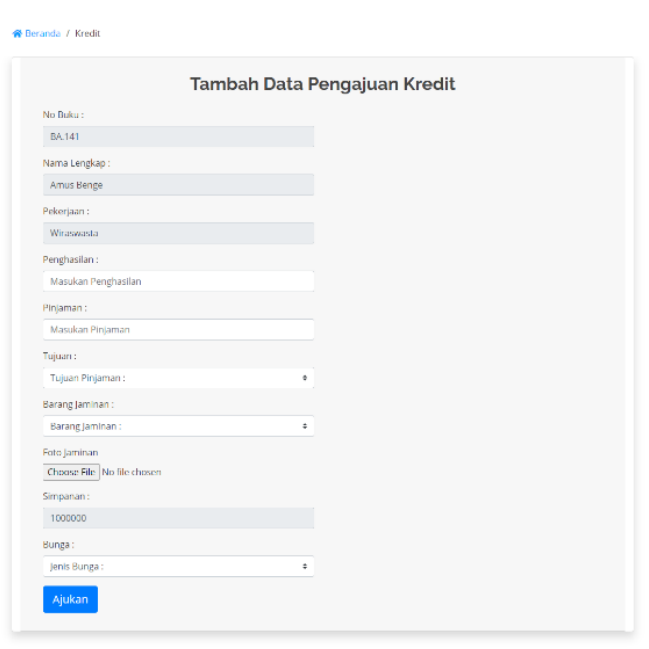

Gbr. 3 Halaman kredit 


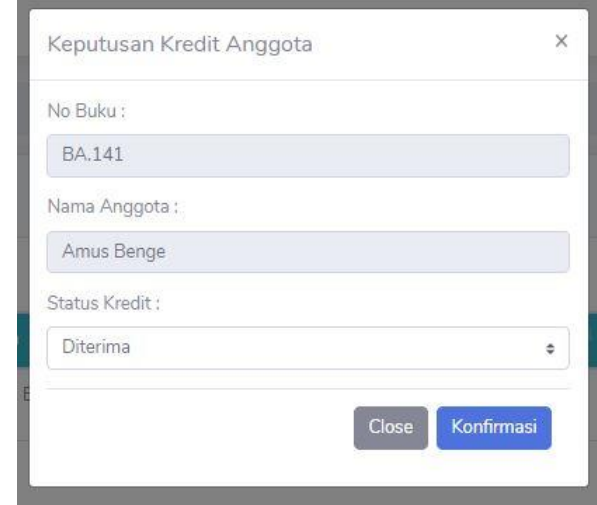

Gbr. 4 Halaman keputusan kredit

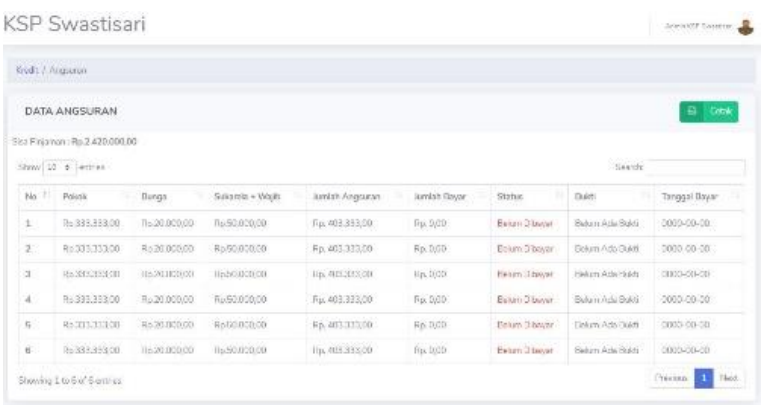

Gbr. 5 Halaman angsuran

\section{B. Pengujian}

TABEL IV CONTOH KASUS DAN PEMETAAN GAP

\begin{tabular}{|c|c|c|c|c|c|c|c|}
\hline \multirow{2}{*}{ Nama } & \multicolumn{6}{|c|}{ Kriteria } & \multirow{6}{*}{ Nilai } \\
\hline & $\mathrm{C} 1$ & $\mathrm{C} 2$ & $\mathrm{C} 3$ & C4 & C5 & C6 & \\
\hline $\begin{array}{l}\text { Anastasia } \\
\text { Kaja }\end{array}$ & 2 & 4 & 5 & 5 & 2 & 3 & \\
\hline $\begin{array}{l}\text { Maria } \\
\text { Ruby }\end{array}$ & 3 & 5 & 3 & 3 & 3 & 4 & \\
\hline $\begin{array}{l}\text { Markus } \\
\text { Lapu }\end{array}$ & 5 & 7 & 7 & 5 & 4 & 6 & \\
\hline $\begin{array}{l}\text { Jhon } \\
\text { Takaen }\end{array}$ & 1 & 1 & 3 & 2 & 2 & 2 & \\
\hline $\begin{array}{c}\text { Nilai } \\
\text { Pencapaian }\end{array}$ & 1 & 1 & 3 & 2 & 2 & 2 & \\
\hline $\begin{array}{l}\text { Anastasia } \\
\text { Kaja }\end{array}$ & 1 & 3 & 2 & 3 & 0 & 1 & \multirow{4}{*}{ Gap } \\
\hline $\begin{array}{l}\text { Maria } \\
\text { Ruby }\end{array}$ & 2 & 4 & 0 & 1 & 1 & 2 & \\
\hline $\begin{array}{l}\text { Markus } \\
\text { Lapu }\end{array}$ & 4 & 6 & 4 & 3 & 2 & 4 & \\
\hline $\begin{array}{l}\text { Jhon } \\
\text { Takaen }\end{array}$ & 0 & 0 & 0 & 0 & 0 & 0 & \\
\hline
\end{tabular}

\section{1) Pembobotan}

Dari data anggota tersebut selanjutnya kita akan menentukan nilai profil pencapaian yang sudah ditentukan. Dari nilai-nilai tersebut akan dilakukan proses perhitungan gap antara nilai profil nasabah dengan nilai profil pencapaian. Berikut adalah tabel nilai pencapaian:
TABEL V

BOBOT NILAI GAP

\begin{tabular}{|c|c|c|}
\hline No & Selisih & Bobot \\
\hline 1 & 0 & 5 \\
\hline 2 & 1 & 4.5 \\
\hline 3 & -1 & 4 \\
\hline 4 & -2 & 3.5 \\
\hline 5 & 2 & 3 \\
\hline 6 & 3 & 2.5 \\
\hline 7 & -3 & 2 \\
\hline 8 & 4 & 1.5 \\
\hline 9 & -4 & 1 \\
\hline 10 & 5 & 0.5 \\
\hline 11 & -5 & 0 \\
\hline 12 & 6 & -1 \\
\hline
\end{tabular}

Dengan demikian bobot nilai dari tiap anggota adalah sebagai berikut:

TABEL VI PEMBOBOTAN

\begin{tabular}{|l|c|c|c|c|c|c|}
\hline \multirow{2}{*}{ Nama } & \multicolumn{5}{|c|}{ Kriteria } \\
\cline { 2 - 7 } & $\mathrm{C} 1$ & $\mathrm{C} 2$ & $\mathrm{C} 3$ & $\mathrm{C} 4$ & $\mathrm{C} 5$ & $\mathrm{C} 6$ \\
\hline $\begin{array}{l}\text { Anastasia } \\
\text { Kaja }\end{array}$ & 4.5 & 2.5 & 3.5 & 2.5 & 5 & 4.5 \\
\hline $\begin{array}{l}\text { Maria } \\
\text { Ruby }\end{array}$ & 3.5 & 1.5 & 5 & 4.5 & 4.5 & 3.5 \\
\hline $\begin{array}{l}\text { Markus } \\
\text { Lapu }\end{array}$ & 1.5 & -1 & 1.5 & 2.5 & 3.5 & 1.5 \\
\hline $\begin{array}{l}\text { Jhon } \\
\text { Takaen }\end{array}$ & 5 & 5 & 5 & 5 & 5 & 5 \\
\hline
\end{tabular}

2) Perhitungan core factor dan secondary factor

- Anastasia Kaja NCF: $(4.5+2.5+3.5+4.5) / 4=3.75$ NSF: $(2.5+5) / 2=3.75$

- Maria Ruby

NCF: $(3.5+1.5+5+3.5) / 4=3.375$

NSF: $(4.5+4.5) / 2=4.5$

- Markus Lapu

NCF: $(1.5+(-1)+1.5+1.5) / 4=0.875$

NSF: $(2.5+3.5) / 2=3$

- Jhon Takaen

NCF: $(5+5+5+5) / 4=5$

NSF: $(5+5) / 2=5$

\section{3) Pencapaian perhitungan nilai total}

Berdasarkan hasil perhitungan setiap kriteria diatas, selanjutnya dihitung nilai total berdasarkan persentase dari core factor (60\%) dan secondary factor (40\%):

Rumus $(60 \% * \mathrm{NCF})+40 \% * \mathrm{NSF}=N$

- Anastasia kaja $(60 \% * 3.75)+40 \% * 3.75=3.75$

- Maria ruby $(60 \% * 3.375)+40 \% * 4.5=3.825$

- Markus lapu $(60 \% * 0.875)+40 \% * 3=1.725$

- Jhon takaen $(60 \% * 5)+40 \% * 5=5$ 
TABEL VII

PENCAPAIAN PERHITUNGAN NILAI TOTAL

\begin{tabular}{|c|c|c|c|c|c|c|c|c|c|}
\hline \multirow{2}{*}{ Nama } & \multicolumn{6}{|c|}{ Kriteria } & \multirow{2}{*}{$\mathrm{NCF}$} & \multirow{2}{*}{ NSF } & \multirow{2}{*}{$\mathrm{N}$} \\
\hline & $\mathrm{C} 1$ & $\mathrm{C} 2$ & $\mathrm{C} 3$ & $\mathrm{C} 4$ & $\mathrm{C} 5$ & C6 & & & \\
\hline $\begin{array}{l}\text { Anastasia } \\
\text { Kaja }\end{array}$ & 4.5 & 2.5 & 3.5 & 2.5 & 5 & 4.5 & 3.75 & 3.75 & $32]^{5}$ \\
\hline $\begin{array}{l}\text { Maria } \\
\text { Ruby }\end{array}$ & 3.5 & 1.5 & 5 & 4.5 & 4.5 & 3.5 & 3.375 & 4.5 & 3.825 \\
\hline $\begin{array}{l}\text { Markus } \\
\text { Lapu }\end{array}$ & 1.5 & -1 & 1.5 & 2.5 & 3.5 & 1.5 & 0.875 & 3 & 1.725 \\
\hline $\begin{array}{l}\text { Jhon } \\
\text { Takaen }\end{array}$ & 5 & 5 & 5 & 5 & 5 & 5 & 5 & 5 & {$[3]$} \\
\hline
\end{tabular}

\section{4) Penentuan keputusan}

Dari hasil perhitungan total diatas, selanjutnya ditentukan anggota yang kreditnya diterima dilihat dari rata-rata nilai total yang diperoleh, rata-rata nilai total yang di pakai koperasi adalah 2.5

TABEL VIII

PENENTUAN KEPUTUSAN

\begin{tabular}{|l|c|l|}
\hline \multicolumn{1}{|c|}{ Nama } & Hasil & \multicolumn{1}{|c|}{ Keterangan } \\
\hline Anastasia Kaja & 3.75 & Diterima \\
\hline Maria Ruby & 3.825 & Diterima \\
\hline Markus Lapu & 1.725 & Ditolak \\
\hline Jhon Takaen & 5 & Diterima \\
\hline
\end{tabular}

\section{KESIMPULAN}

Berdasarkan hasil penelitian, maka dapat disimpulkan bahwa:

1. Dengan dibangunnya aplikasi penentuan kredit. Maka pihak koperasi dapat mengefisiensi waktu serta mengurangi kelalaian kredit

2. Dengan adanya metode profile matching dalam menyelesaikan permasalahan kredit menggunakan kriteria-kriteria sehingga memudahkan pihak koperasi dalam menentukan kredit yang layak diterima.

3. Dengan dibangunnya aplikasi penentuan kredit, anggota dapat dengan mudah melakukan pendaftaran dan melakukan pengajuan kredit.

4. Anggota juga dapat melakukan transaksi seperti angsuran dan simpanan.

\section{REFERENSI}

Pinem, A. P. R., Pungkasanti, P. T., \& Widodo, E. (2017). Implementasi Profile Matching Untuk Pemberian Kredit Kedua Pada Koperasi Simpan Pinjam. Simetris : Jurnal Teknik Mesin, Elektro Dan Ilmu Komputer, 8(2), 539. https://doi.org/10.24176/simet.v8i2.1366

Syarifudin, A., \& Ananta, A. Y. (2015). Rancang Bagun Sistem Pendukung Keputusan Kelayakan Pemberian Kredit Menggunakan Metode Profile Matching. Prosiding Seminar Informatika Aplikatif 2015.

2.725 ttp://jti.polinema.ac.id/index.php/seminar-informatikaaplikatif-siap/

Tharo, Z., \& Utama Siahaan, A. P. (2016). Profile Matching in Solving Rank Problem. IOSR Journal of Electronics and Communication Engineering, 11(05), 73-76. https://doi.org/10.9790/2834-1105017376

[4] purwanto, H. (2017). Penerapan Metode Profile Matching Dalam Sistem Pendukung Keputusan Penilaian Kinerja Karyawan Pada Pt. Hyundai Mobil Indonesia Cabang Kalimalang.

[5] Rohayani, H. (2013). Analisis Sistem Pendukung Keputusan Dalam Memilih Program Studi Menggunakan Metode Logika Fuzzy. 530-539. 